\title{
A Novel Hybrid Polymer Network for Efficient Anticorrosive and Antibacterial Coatings
}

Yaqi Fu ${ }^{\mathrm{a}, \dagger}$, Mengsha Cai ${ }^{\mathrm{b}, \dagger}$, Eryong Zhang ${ }^{\mathrm{b}}$, Simeng Cao ${ }^{\mathrm{b}}$, Peijun $\mathrm{Ji}^{\mathrm{b}}{ }^{, *}$

${ }^{a}$ Department of Biochemical Engineering and ${ }^{b}$ Department of Chemical Engineering, Beijing University of Chemical Technology, Beijing, 100029, China

${ }^{*}$ Corresponding author. Tel. +861064446249.

E-mail address:jipj@mail.buct.edu.cn

${ }^{\dagger}$ Y.F. and M.C. contributed equally to this work. 
Pull-off adhesion. Adhesion strength of the PDSHP layer coating on the stainless steel substrates was determined using pull-off test method by the ASTM D4541 procedure. Pull-off adhesion tester (DEFELSKO) was used. The aluminium dolly was glued on the PDSHP layer with Araldite 2015 epoxy adhesive (Huntsman advanced materials, Germany). Samples were then kept at room temperature for $24 \mathrm{~h}$ to ensure that the glue fully cured. The test started with pulling the dolly. During pulling the dolly, the glue on the SS-PDSHP samples has broken off (Figure S1). The color and surface at the places indicated by arrows look as the same as that at other places outside the glue circles (Figure S1). It is indicated that the pull-off test has no damage to the PDSHP layer. Therefore we conclude that the PDSHP layer adhered to the stainless steel very strongly.

Electrochemical impedance spectroscopy (EIS) measurement. EIS measurements were performed on a Princeton Applied Research Parstat 2273 instrument. The Zview software was used for experimental control and acquisition of data. EIS spectra were obtained with an $\mathrm{AC}$ amplitude of $\pm 10 \mathrm{mV} \mathrm{rms}$ and a frequency range of $10^{-2}-10^{5} \mathrm{~Hz}$. Measurements of cyclic voltammetry were carried out in a three-electrode cell at room temperature. $3.5 \%$ sodium chloride was used as the background electrolyte.

Table S1. Infrared bands of the hybrid polymer coatings on SS sample surfaces

\begin{tabular}{|c|c|c|}
\hline Wavenumber & $\left(\mathrm{cm}^{-1}\right)$ & Assignment \\
\hline 3395 & & $\mathrm{OH}$ and $\mathrm{NH}$ stretching modes \\
\hline 3433 & & $\mathrm{OH}$ and $\mathrm{NH}$ stretching modes \\
\hline 2941 & & $\mathrm{CH}$ stretching vibrations \\
\hline 2945 & & $\mathrm{CH}$ stretching vibrations \\
\hline 2892 & & $\mathrm{CH}$ stretching vibrations \\
\hline 2883 & & $\mathrm{CH}$ stretching vibrations \\
\hline 1661 & & $\operatorname{vring}(\mathrm{C}=\mathrm{O})$ \\
\hline 1657 & & $\operatorname{vring}(\mathrm{C}=\mathrm{O})$ \\
\hline 1572 & & $\operatorname{Vring}(C=C), \operatorname{vring}(C=N)$ \\
\hline 1563 & & $\operatorname{Vring}(\mathrm{C}=\mathrm{C}), \operatorname{vring}(\mathrm{C}=\mathrm{N})$ \\
\hline 1149 & & $\mathrm{C}-\mathrm{N}$ stretching vibration \\
\hline 1140 & & $\mathrm{C}-\mathrm{N}$ stretching vibration \\
\hline
\end{tabular}


1089

1069

920

915

843

766
$\mathrm{Si}-\mathrm{O}-\mathrm{Si}$ asymmetric stretching or $\mathrm{Si}-\mathrm{O}-\mathrm{C}$

$\mathrm{Si}-\mathrm{O}-\mathrm{Si}$ asymmetric stretching or $\mathrm{Si}-\mathrm{O}-\mathrm{C}$

Si-OH stretching

Si-OH stretching

Si-O-Si symmetric stretching

Si-O-Si symmetric stretching

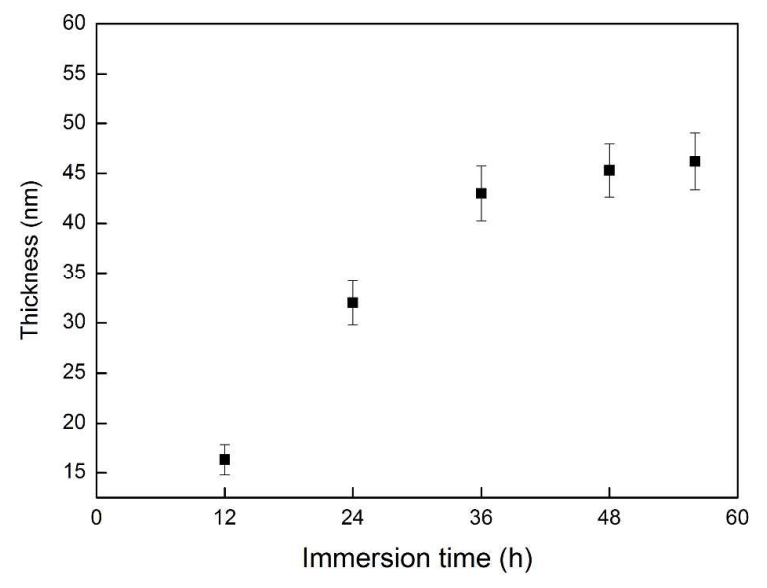

Figure S1. Thickness of the hybrid polymer PDSHP as a function of immersion time in the reaction solutions

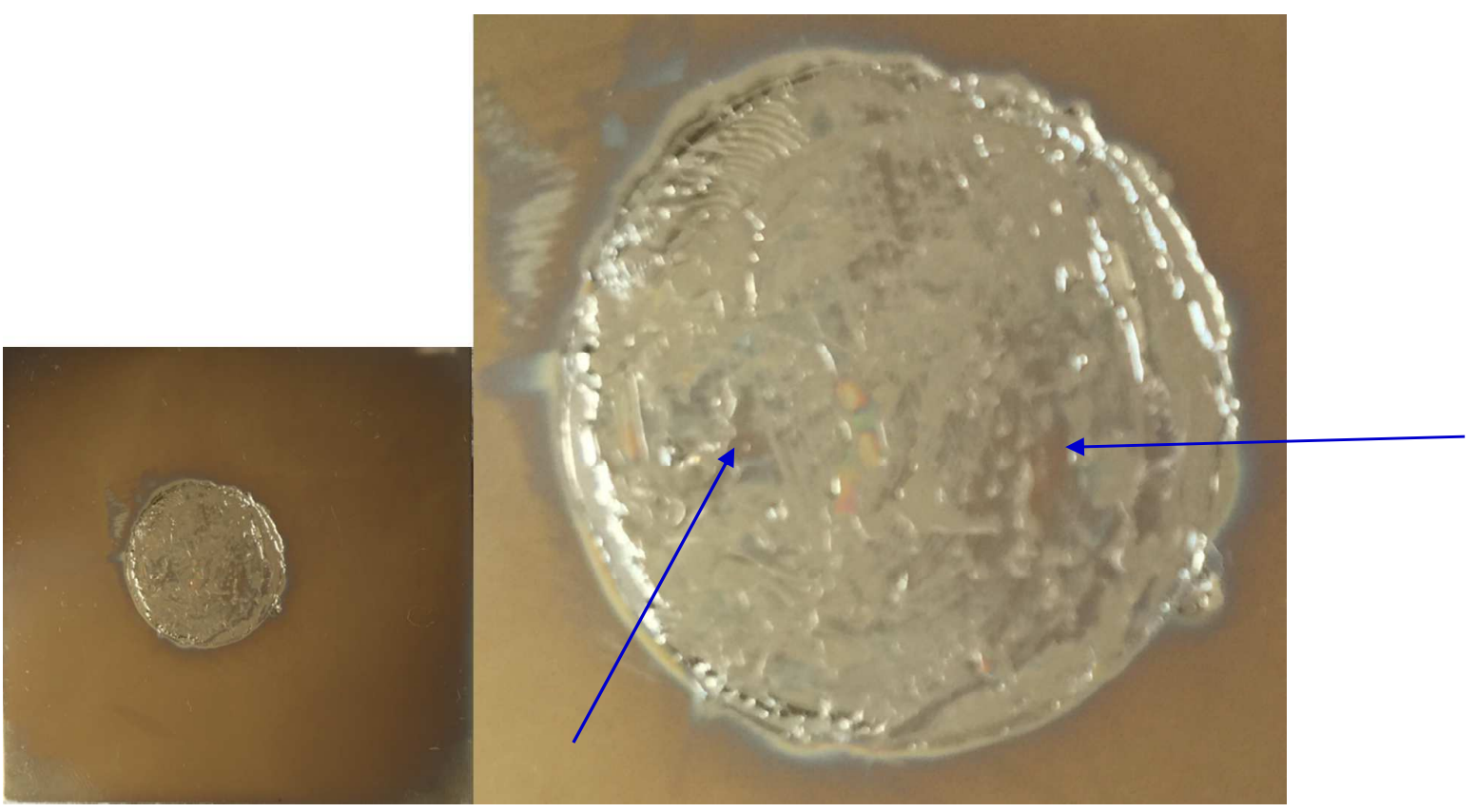

Sample A 


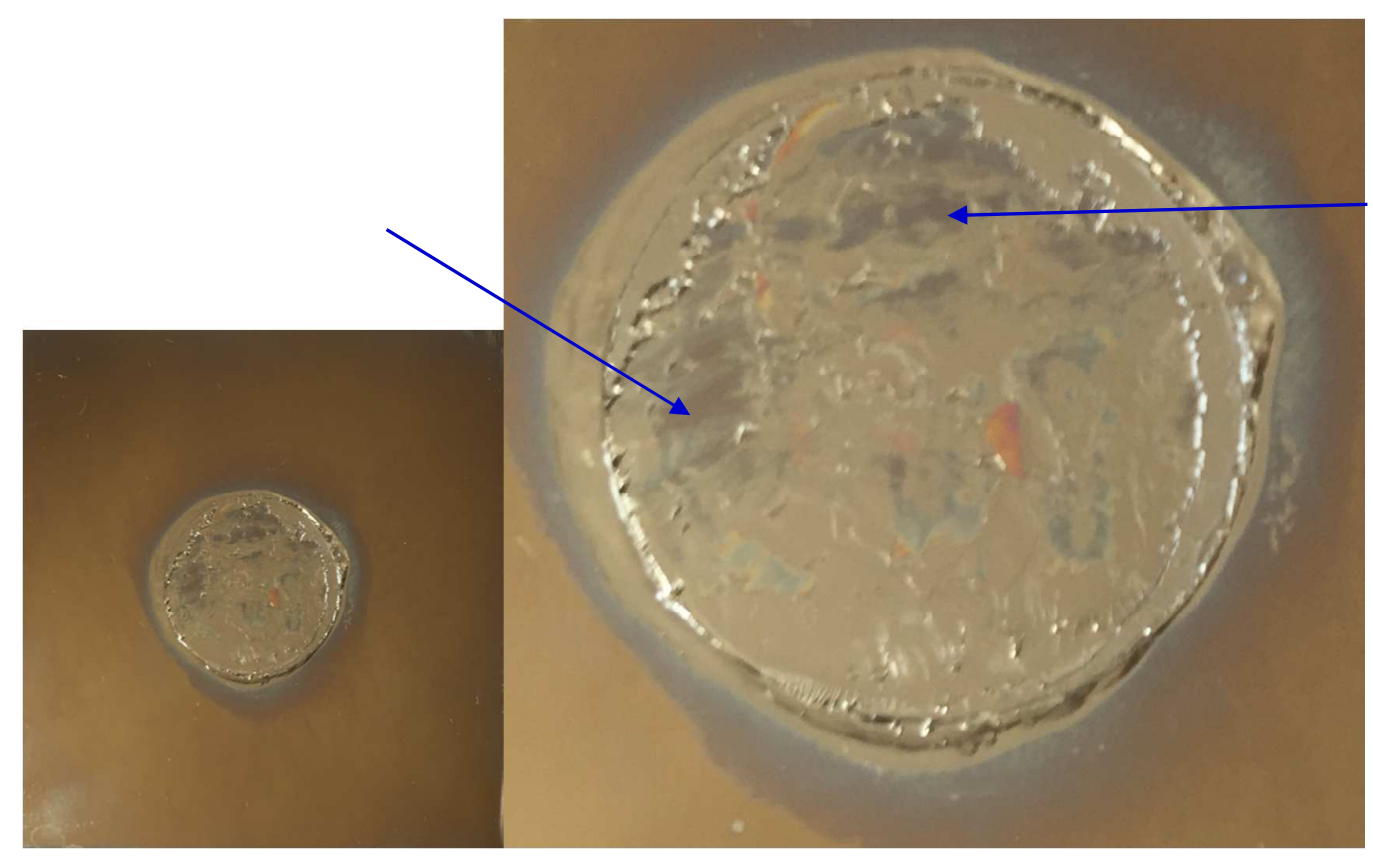

Sample B

Figure S2. Pull-off test for the PDSHP coated SS samples

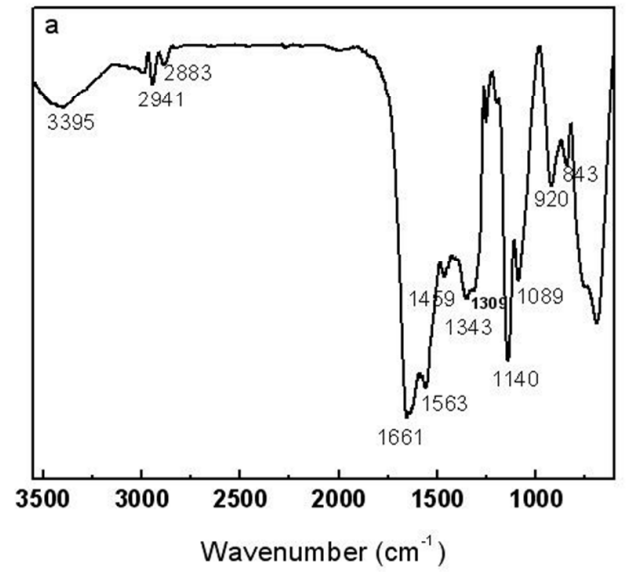

Figure S3. FTIR spectra of SS-PDSHP 


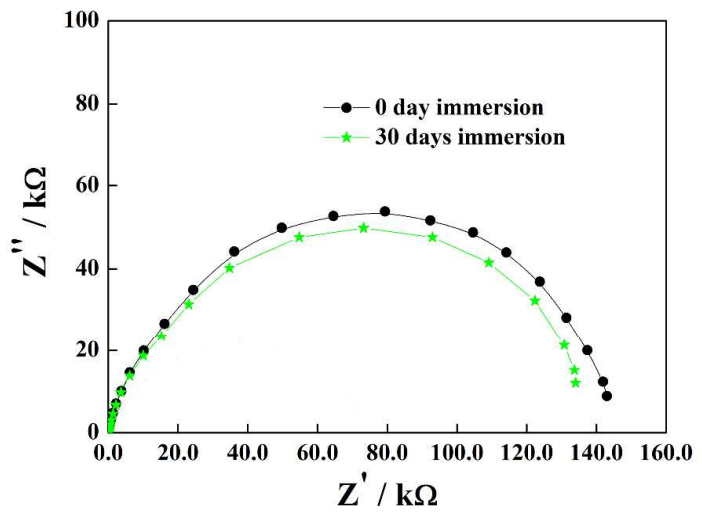

Figure S4. Nyquist plot of SS-PDSHP-PEI-CHPAC after 30 days immersion in artificial seawater

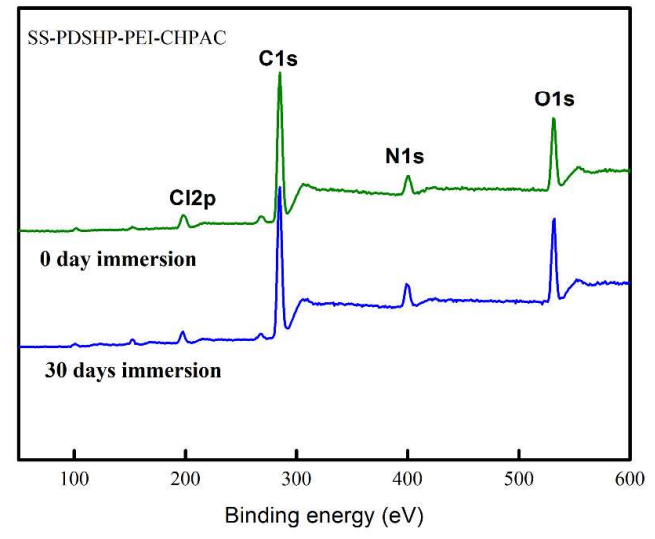

Figure S5. XPS spectrum (in blue) for SS-PDSHP-PEI-CHPAC after 30 days immersion in artificial seawater

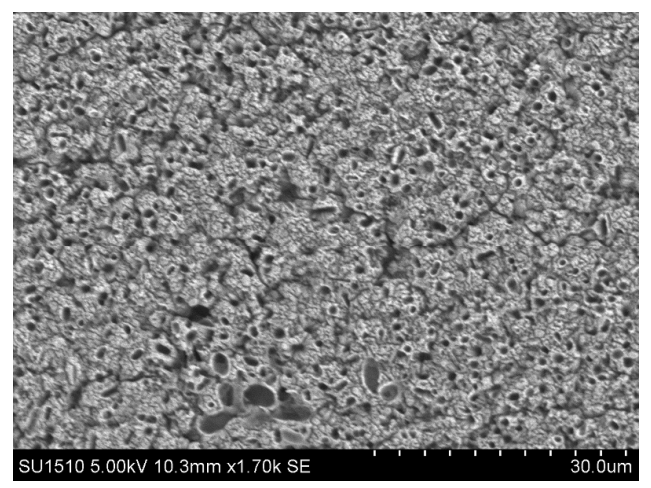

Figure S6. SEM image of the SS-polydopamine coupon after exposure in the articial seawter for 30 days. 